\title{
Imagem corporal, trauma e resiliência: reflexões sobre o papel do professor de Educação Física
}

\author{
Angela Nogueira Neves \\ Escola de Educação Física do Exército - Rio de Janeiro - RJ \\ Karina Mayumi Hirata \\ Universidade Estadual de Campinas - SP \\ Maria da Consolação Gomes Cunha Fernandes Tavares \\ Universidade Estadual de Campinas - SP
}

\begin{abstract}
Resumo
Incitar à reflexão sobre promoção da resiliência no contexto escolar por meio da intervenção intencional do professor de Educação Física é a principal proposta deste ensaio. Para alcançar este propósito, as autoras apoiaram-se em informações científicas já publicadas e em suas próprias observações, oriundas de suas práticas docentes. O presente ensaio inicia-se apresentando a perspectiva psicossomática do desenvolvimento da imagem corporal, uma informação preliminar necessária para a argumentação posterior, na qual conceituamos trauma e resiliência e apontamos argumentos que preconizam o exercício físico e as experiências corporais como fontes de compensação longitudinal para lacunas na identidade corporal. Nossa argumentação se finaliza diferenciando situações de perpetuação do trauma emocional e de desenvolvimento da identidade corporal, apontando o professor de Educação Física como um tutor de resiliência por excelência.
\end{abstract}

Palavras-chave: Educação Física; resiliência; imagem corporal.

\section{Body image, trauma and resilience: \\ a reflection on the role of the physical education teacher}

\begin{abstract}
The main aim of this essay is to stimulate the reflection on the promotion of resilience in school mediated by the intervention of the physical educator in school. We base our arguments on previous scientific evidences as well as on our own observations derived from our teaching experience. Initially we presented the psychosomatic perspective for body identity development. This is necessary preliminary information for further argumentation. We conceptualize trauma and resilience and argue that physical activities and experiences are sources for longitudinal compensation for gaps on body identity. Our argumentation ends with the differentiation between trauma perpetuation and body identity development. We suggest that physical education teachers are resilience tutor par excellence.
\end{abstract}

Keywords: Physical education; resilience; body image.

\section{Imagen corporal, trauma y resiliencia: reflexiones sobre el papel del profesor de Educación Física}

\section{Resumen}

Incitar a la reflexión sobre promoción de la resiliencia en el contexto escolar por intermedio de la intervención intencional del profesor de Educación Física es la principal propuesta de este ensayo. Para alcanzar este propósito, las autoras se apoyaron en informaciones científicas ya publicadas y en sus propias observaciones, oriundas de sus prácticas docentes. El presente ensayo se inicia presentando la perspectiva sicosomática del desarrollo de la imagen corporal, una información preliminar necesaria para la argumentación posterior, en la cual se conceptúa trauma y resiliencia y se apunta argumentos que preconizan el ejercicio físico y las experiencias corporales como fuentes de compensación longitudinal para lagunas en la identidad corporal. Nuestra argumentación se finaliza diferenciando situaciones de perpetuación del trauma emocional y de desarrollo de la identidad corporal, apuntando el profesor de Educación Física como un tutor de resiliencia por excelencia.

Palabras-clave: Educación Física; resiliencia; imagen corporal. 


\section{Introdução}

Imagem corporal é a representação mental do corpo (Schilder, 1980; Tavares, 2003). É singular, baseada na nossa realidade corporal e nos significados de experiências vividas constituídas pelas nossas relações sociais e pelos aspectos de nossa personalidade. A representação mental do corpo não é estática; antes, a imagem corporal é tanto uma estrutura quanto um processo (Shontz, 1969). A imagem corporal desconstrói-se e reconstrói-se sob o cerne estável da identidade, que dá ao sujeito referências primordiais de si. Esse dinamismo relaciona-se com o desenvolvimento da imagem corporal. Possibilita ao sujeito ressignificar elementos de sua vida e incorporá-los, num novo significado, à sua identidade (Schilder, 1980; Tavares, 2003).

Um foco atual e relevante de pesquisas sobre imagem corporal é identificar formas para prevenir os quadros de imagem corporal negativa - marcada por comportamentos, crenças e sentimentos fortemente negativos em relação ao corpo e promover a imagem corporal positiva - que compreende reconhecimento de potencialidades e limites, respeito, cuidado, afeto e proteção ao corpo (Avalos, Tylka \& Wood-Barcalow, 2005; Cash, 2004). Nesta perspectiva, é pertinente considerar que alguns tipos de experiências corporais são particularmente positivos para promover a conexão do indivíduo com sua realidade corporal, ser aceito e se aceitar, elaborar as perdas e reconhecer as vulnerabilidades (Krueger, 2002, 2001). Entre estas experiências destacam-se aquelas que podem emergir durante a prática de atividade física. A atividade física, dirigida ou não, pode ser um meio para retomar o desenvolvimento da imagem corporal, porquanto permite ao sujeito encontrar lugares de afeto, de novas vivências corporais que ofereçam oportunidades de reconstruir a identidade, apesar das lacunas (Cyrulnik, 2004). Segundo Krueger (2002), para alcançar este intento, os trabalhos com exercícios físicos, atividades físicas ou terapias corporais devem permitir uma experiência direta do "eu" corporal e do afeto, sem culpa.

Assim, para os profissionais que trabalham com atividade física e movimento, cria-se uma expectativa sobre suas possibilidades de intervenção para a promoção de uma identidade corporal integrada. Isto é particularmente verdade para os professores de Educação Física Escolar, já que a escola é reconhecida como um meio social relevante na formação do sujeito (Campbell, \& Hausenblas, 2009; Smolak, 2011). Froehlich-Gildhooff e Roennau-Boese (2012) reforçam a importância das escolas que cuidam das crianças para o desenvolvimento destas, pois essas instituições são "centros de socialização" e oferecem boas oportunidades para programas de prevenção. Além disso, segundo os autores, a escola identifica com mais facilidade as necessidades das suas crianças e de seus pais, além de os professores possuírem grande influência sobre a criança e a família. Doll, Dooley e Turner (2011) afirmam que a escola tem a possibilidade de atuar nas lacunas deixadas principalmente pelas desigualdades sociais. Além disso, a escola é responsável pelo desenvolvimento e bem-estar de uma criança por muitos anos, o que influencia significativamente seu futuro.
Para que estas possibilidades se tornem uma ação concreta, a pesquisa e a atuação profissional devem ultrapassar a prática recorrente de avaliar como o sujeito percebe, reage, avalia e investe em sua aparência física e de ver os padrões de performance como qualificadores de participação nas atividades físicas e esportivas. Devem-se incluir a função do corpo, as sensações corporais, a competência física e a estima corporal. Algoe e Friedrickson (2011) e Morgan (2010) reforçam esse argumento ao afirmarem que a avaliação de intervenções que se proponham a ser fontes de recursos para o desenvolvimento do sujeito devem-se focar nas respostas emocionais e nas sensações do corpo, como por exemplo, maior flexibilidade em lidar com o outro, sensação de bem-estar, relaxamento, divertimento, senso de maestria e de capacidade de lidar com problemas do dia a dia, aumento da empatia e do sentido da vida e melhora dos relacionamentos sociais. Talvez, mais relevante do que a adoção dessa perspectiva ampliada, a pesquisa sobre a intervenção para a promoção de uma imagem corporal positiva através do movimento deva ser precedida pela compreensão do papel do professor de Educação Física como um promotor de desenvolvimento da identidade corporal e um tutor de resiliência. O professor de Educação Física, com base nas discussões que cercam a imagem corporal positiva e na resiliência, pode contribuir para que seus alunos - crianças ou adolescentes - sejam capazes não só de suportar as dificuldades, mas também de proporcionar recursos para que eles saiam fortalecidos de cada situação que possa comprometer seu desenvolvimento.

Este ensaio se dirige a este ponto. Para fundamentar a argumentação aqui desenvolvida, situa-se o papel da experiência corporal no desenvolvimento da identidade corporal, conceituam-se trauma e resiliência e apontam-se argumentos que preconizam o exercício físico e as experiências corporais dele advindas como fontes de compensação longitudinal de interrupções ocorridas no processo de estruturação e desenvolvimento da identidade corporal. A argumentação se finaliza diferenciando situações de perpetuação do trauma emocional e de desenvolvimento da identidade corporal, apontando aos professores de Educação Física que pretendam assumir o papel de tutor de resiliência as condições para cumprir esse papel, que é dele por excelência.

\section{Experiência corporal e o desenvolvimento da Imagem corporal}

A premissa que sustenta o papel da experiência corporal no desenvolvimento da imagem corporal é a de que a noção de existência se constitui por meio da manipulação do corpo para os cuidados de alimentação e higiene, do aconchego e das carícias e da ressonância dos estados internos através do cuidador. É por meio da ação sobre o corpo físico que se nasce sujeito, e então o corpo deixa de ser apenas carne e passa a ser existência do sujeito. Em outras palavras, no parto a mãe dá à luz o corpo físico e traz o corpo existencial ao mundo "linguageiro" por meio de 
seu olhar. Seu desejo pelo seu bebê é o ponto de partida para o reconhecimento dele em sua singularidade e desejo (Dolto, 2001; Schilder, 1980). A ressonância contingente e empática do primeiro cuidador para com a criança é a base fundamental da constituição da identidade corporal (Krueger, 2002, 2002a).

Para pensar o desenvolvimento da Imagem corporal na perspectiva psicodinâmica são particularmente interessantes as concepções sobre as etapas de desenvolvimento de Krueger (2002, 2002a, 2001), por ressaltarem a importância das experiências corporais precoces no processo de diferenciação do ser humano. Para o autor, as experiências corporais primárias constituem a base para a organização das experiências corporais atuais. Assim, a sintonia próxima e diligente do cuidador com a criança, reconhecendo e respondendo adequadamente a todos os contatos motores e sensoriais, forma o self corporal da criança como recipiente e base para o self psicológico em evolução.

Krueger (2001) propõe a existência de três estágios no desenvolvimento do self corporal: (1) experiências psíquicas precoces; (2) definição dos limites corporais e reconhecimentos dos estados corporais; e (3) definição e coesão do self corporal como base da consciência do self. No primeiro estágio (experiências psíquicas precoces) o sentido do self é dado especialmente pelas sensações táteis (mas também pelos estímulos visuais e auditivos), que permitem uma discriminação do corpo próprio em relação ao ambiente. Nesta fase as respostas empáticas e a continência do primeiro cuidador têm papel fundamental na formação inicial dos limites corporais e no reconhecimento dos estados corporais. No segundo estágio (definição dos limites corporais e reconhecimentos dos estados corporais) há o crescimento do senso de realidade, que emerge da delimitação mais precisa dos limites corporais e do reconhecimento dos estados internos, que sintetizam a integração das experiências corporais vividas pela criança. O olhar do cuidador e interações recíprocas continuam sendo de importância para a unificação das experiências vividas pela criança. $O$ terceiro estágio (definição e coesão do self corporal como base da consciência do self) se inicia quando a criança se reconhece no espelho e quando começa a dizer "não", indicações de que a autonomia e a consciência de si estão emergindo. Sabe-se que quando tudo ocorre suficientemente bem, isto é, quando o sujeito não sofre uma interrupção importante no desenvolvimento do self corporal, poder-se-á observar que o sujeito reconhece e comunica com maior precisão seus estados corporais. O sujeito é também atento à realidade concreta de seu corpo e capaz de reconhecer o que pertence a si e o que é do mundo, além de ter o senso de que existe corporalmente. Nesse estágio há uma unidade entre mente e corpo com uma coesão em evolução da imagem e do self corporal. Em suma, o self psicológico e o self corporal existem integrados (Krueger, 2002).

Em complementação a esta perspectiva apresentada, que considera as experiências corporais precoces fundamentais para o desenvolvimento da imagem corporal, afirma-se que a relevância das experiências corporais para o desenvolvimento da Imagem corporal não é limitada aos primeiros anos de vida (Schilder, 1980), pois é contínuo o processo de ter experiências e de explorar o corpo (Tavares, 2003). As experiências corporais diversas que o sujeito tem ao longo da vida são um recurso essencial para a contínua estruturação da identidade corporal, uma vez que a vivência das sensações corporais advindas destas experiências possibilita ao sujeito reconhecer-se em sua unidade corporal, cuja importância central está na formação de uma identidade integrada (Schilder, 1999; Shontz, 1990; Tavares, 2003). Este processo dinâmico é o que permite que as lacunas no desenvolvimento advindas, por exemplo, da superinvasividade, da superestimulação, da falta de percepção e de resposta empática por parte do cuidador ou do outro significante não sejam uma sentença de vida, mas sejam passíveis de reestruturações longitudinais (Tavares, 2003).

\section{Trauma, resiliência e imagem corporal}

O trauma ocorre quando se é atordoado, oprimido, quando se é incapaz de ter uma reação capaz de enfrentar o evento atordoante, ficando a sensação de desamparo, desesperança, de estar desligado do corpo (Levine, \& Kline, 2007). O que define o trauma não é o evento em si, mas antes, os recursos (ou a falta deles) de que o sujeito dispõe para responder ao evento (Levine, \& Frederick, 1999). O trauma pode ser caracterizado por ações pequenas e ordinárias, que ocorrem de forma contínua e ao longo do tempo causam um desvio de percurso que impede a pessoa de viver plenamente, sendo chamado, então, de trauma de desenvolvimento. Por sua vez, o trauma causado por um evento único ou extraordinário é chamado de trauma de choque (Levine, \& Frederick, 1999; Levine, \& Kline, 2007).

O trauma - que desvia o sujeito de seu desenvolvimento "normal" - destitui as experiências presentes de seus valores reais, mantendo sempre atuais os espaços de silêncio no corpo (Cyrulnik, 2005). Pessoas traumatizadas são incapazes de superar a ansiedade de sua experiência e permanecem sobrecarregadas pelos acontecimentos, derrotadas e aterrorizadas. As defesas protetoras usadas no trauma levam à alteração da consciência e à desconexão das sensações do corpo, impactando a memória, a coesão e a consciência de si (Krueger, 2001, 2002, 2002a). Essas pessoas tornam-se mais propensas a desintegrações, passando a usar seus sistemas sensoriais de forma aguda para criar uma representação mais explícita de si, através da dor autoinfligida, excesso de exercícios, fome e experiências sexuais fragmentadas. Levine e Kline (2007) identificaram que os traumas sofridos pelas crianças se expressavam por meio de problemas de comportamento, agressividade, hiperatividade, vícios, fobias, ansiedade e falta de confiança.

O trauma paralisa o desenvolvimento do sujeito e, consequentemente, altera o dinamismo da imagem corporal: o sujeito não se "desfaz", mas também, desconectado de si mesmo, não se reconstrói dinamicamente. A representação do trauma passa a fazer parte da identidade do sujeito, que 
se mantém vivo, porém limitado (Cyrulnik, 2004). Por outro lado, o trauma não é uma sentença perpétua, ele pode ser renegociado. Cyrulnik (2004) ressalta que o trauma não pode ser revertido depois de ocorrido, mas pode ser reelaborado e ressignificado, reduzindo o impacto provocado por estresses ou infortúnios ocorridos com crianças, adolescentes e suas famílias. Explica o autor:

Um ferimento precoce ou um grave choque emocional deixam um traço cerebral e afetivo que permanece dissimulado sob a retomada do desenvolvimento. O tecido portará uma lacuna ou uma malha particular que irá alterar a continuação da tecedura. Poderá se tornar um tecido bonito e quente, mas será diferente. O distúrbio é reparável, às vezes até para melhor, mas não é reversível (Cyrulnik, 2004, p. 113).

Para retomar o desenvolvimento é necessário haver um potencial de reação suficiente para sair do efeito imobilizante do trauma. Esse potencial de reação pode ser chamado de resiliência. O termo resiliência pode ser definido como um processo no qual a pessoa atingida por uma adversidade reequilibra-se, reage e continua a vida, mesmo que num percurso diferente do original (Dyer, \& McGuinness, 1996), ou como o processo que permite retornar a algum tipo de desenvolvimento, apesar do traumatismo e de condições adversas. A ferida ou falta que interrompeu o processo de desenvolvimento não se apaga na retomada da estruturação da identidade, portanto a resiliência não tem relação com invulnerabilidade ou êxito social (Cyrulnik, 2009). Com o trauma estabelecido, a resiliência está relacionada à superação que abrange um processo de ressignificar, e não de eliminar o acontecimento, pois esse acontecimento passa a fazer parte da história da pessoa (Cyrulnik, 2005).

Os recursos que cada sujeito possui para ressignificar o trauma são chamados de pilares de resiliência. Estes recursos podem ser classificados em quatro categorias: "eu tenho", "eu sou", "eu estou" e "eu posso". Na categoria "eu tenho" estão os fatores relacionados ao apoio; "eu posso" agrupa os fatores relacionados às habilidades interpessoais e de resolver conflitos; nas categorias "eu sou" e "eu estou" concentram-se os fatores relacionados ao desenvolvimento da força intrapsíquica (Grotberg, 2005). A despeito da categorização, têm-se identificado características que aparecem frequentemente em pessoas consideradas resilientes e que foram organizadas como pilares da resiliência. São elas: a introspecção, a independência, a capacidade de se relacionar, a iniciativa, o humor, a criatividade, a moralidade e a autoestima consistente (Mellilo, \& Ojeda, 2005). Além disso, a percepção consciente do corpo acessada pela sensopercepção e outras experiências que permitam a conexão do indivíduo com sua realidade corporal de ser aceito e de se aceitar, de elaborar as perdas e de reconhecer as vulnerabilidades, podem levar ao estabelecimento de uma representação interna acurada do corpo e a um senso de identidade, fornecendo compensações às desintegrações anteriormente vivenciadas (Krueger, 2002; Levine, \& Frederick, 1999). Estes recursos também podem ser considerados competências de uma pessoa resiliente.

A retomada do desenvolvimento não é um processo definitivo, mas é um processo dinâmico, marcado pela ameaça de desintegração:

(...) a cicatriz nunca é segura. É uma fenda no desenvolvimento de sua personalidade, um ponto fraco que pode sempre se dilacerar sobre os golpes do destino. Essa rachadura obriga... a trabalhar incessantemente sua metamorfose interminável. Então, poderá levar uma vida... bela, porém frágil, porque nunca poderá esquecer seu passado.... Mas... poderá pensar nele de maneira suportável (Cyrulnik 2004, p. 4).

Por isso o sujeito resiliente precisa contar com seus recursos, mas também com um ambiente social favorável para conseguir manter íntegra sua identidade, reestabelecida no neodesenvolvimento. Este ambiente social é dado fundamentalmente pela família (provendo estabilidade, respeito mútuo, apoio e suporte) e pelas relações sociais estabelecidas no relacionamento com amigos, professores e outras pessoas significativas, fatores que devem reforçar o sentimento do sujeito de ser uma pessoa querida e amada. O sujeito resiliente necessita de uma ou mais pessoas que promovam oportunidades de ressignificações de experiências, deem-lhe afeto, reconheçam e valorizem sua singularidade (Junqueira, \& Deslandes, 2003). Podemos chamar estas pessoas de tutoras de resiliência.

Tutores de resiliência são aqueles que oferecem suporte e um espaço seguro para a retomada do desenvolvimento inflectido pelo ferimento (Cyrulnik, 2004). São pessoas significativas na vida do sujeito, que o ajudarão a retomar seu desenvolvimento, auxiliando-o na representação do trauma (Cyrulnik, 2005) por meio do estímulo ao desenvolvimento dos fatores de resiliência dos pilares eu soul estou, eu tenho e eu posso definidos por Grotberg (2005). Nos estudos confirmatórios de resiliência, o que é unânime entre os pesquisadores é o fato de que todos os sujeitos que se tornaram resilientes tinham pelo menos uma pessoa (familiar ou não) que os aceitou de forma incondicional e independente de seus temperamento, aspecto físico ou inteligência. Esses sujeitos precisam contar com alguém e, ao mesmo tempo, sentir que seus esforços, sua competência e autovalorização são reconhecidos e fomentados (Melillo, Estamatti, \& Cuestas, 2005). O desenvolvimento ou não do potencial de resiliência nos sujeitos depende da interação da pessoa com seu entorno humano (Cyrulnik, 2004). Na escola o sujeito pode encontrar em seus professores uma pessoa significante, que the ofereça continência em seu processo de crescimento (Horning, \& Rouse, 2002). O professor, especialmente o de Educação Física, pode se tornar um tutor de resiliência para seus alunos, uma vez que, por meio do exercício físico orientado e da atividade física, pode oferecer oportunidades para o processo resiliente. 


\section{O professor de Educação Física como tutor de resiliência}

Ao considerar o professor de Educação Física como um tutor de resiliência, capaz de ofececer suporte à retomada do desenvolvimento da imagem corporal, não se deve perder de vista que este está diretamente relacionado às experiências corporais e que o movimento corporal é a fonte primordial destas experiências. É através do movimento que existimos e agimos no mundo. Se bem conduzida, a atividade física permite vivenciar sensações singulares capazes de propiciar um melhor reconhecimento do próprio corpo, seus limites e suas possibilidades (Tavares, 2003).

Ratificando esta afirmação, Bentzen, Jarlanaes e Levine (2004) consideram que todo o sistema motor está envolvido em expressar aspectos da existência que podem ser lidos por meio do movimento, postura, padrões de extensão e flexão corporais. Pensamentos, sentimentos e imagens que emergem quando um músculo é ativado - sendo tocado ou estando em ação contrátil - revelam a experiência relacionada àquela função motora ou por ela representada. Assim, quando o sujeito se movimenta, representações de trauma acompanham seu movimento, e o profissional atento a estes aspectos pode promover situações que ressignifiquem estas representações. Assim, a prática de atividade física pode ser um momento de evocação do potencial de resiliência e, consequentemente, um meio para retomar o desenvolvimento da imagem corporal, uma vez que permite ao sujeito encontrar lugares de afeto e novas experiências corporais que lhe ofereçam oportunidades de reconstruir a identidade, apesar das feridas precoces (Cyrulnik, 2004).

Iza e Mello (2009) enfatizam que durante as atividades de movimento é necessário que os alunos sejam considerados como seres inteiros, e não limitados apenas ao aspecto motor, o que implica uma postura de respeito ao ritmo do aluno e a valorização de cada uma de suas descobertas (motoras ou não), e a criação de situações nas quais sejam incitados a resolver problemas durante a execução dos movimentos.

Para Gilligan (1999), professores de Educação Física e profissionais que trabalham com atividades culturais têm um papel crucial como tutores de resiliência, uma vez que criam oportunidades de vivências positivas e um espaço de ressignificação da realidade. Os desafios do esporte, os novos contatos sociais, a sensação de sucesso na realização de um movimento precisamente técnico, o senso de maestria e o divertimento encontrado no exercício físico são os elementos dos quais as pessoas podem se beneficiar na prática esportiva. Morgan (2010) afirma que o divertimento e a satisfação advindos do movimento são aprendidos no corpo, e que é a partir do corpo que estas experiências ganham novo sentido.

Segundo Krueger (2002), para se alcançar este intento, os trabalhos com exercícios físicos, atividades físicas ou terapias corporais devem permitir uma experiência direta do self corporal e do afeto, sem culpa. Sobre isto afirma Tavares, 2003 (p. 104):
Facilitar o desenvolvimento da imagem corporal requer a preservação da identidade do outro, o que implica o reconhecimento e a validação de suas percepções (...) O desenvolvimento de nossa identidade corporal está ligado à vivência e ao reconhecimento de nossas percepções. Isso permite constante coesão dessas percepções e construção de um "eu corporal" verdadeiro.

Para isto ser uma realidade, premissas básicas são a capacidade do aluno de entrar em contato consigo mesmo, o oferecimento de um ambiente acolhedor e a existência de um professor capacitado para suportar as demandas de seu aluno - o que exige preparo técnico e a vivência de suas próprias limitações e capacidades (Krueger, 2002; Tavares, 2003).

Conforme Campbell \& Hausenblas (2009), a despeito de seu potencial uso como uma alternativa promissora para a retomada do desenvolvimento, nem sempre o exercício físico tem esse papel. O olhar atento consegue identificar situações que auxiliam na perpetuação de uma identidade corporal fragmentada. Em As cidades Invisíveis, a descrição da cidade Anastácia, feita por Marco Polo ao imperador Kublai Khan, ilustra esse alto preço que a falta de conhecimento e consciência de própria existência pode cobrar.

Sobre isso observa Calvino, 1990 (p. 16):

A cidade aparece como um todo no qual nenhum desejo é desperdiçado e do qual você faz parte, e, uma vez que aqui se goza tudo o que não se goza em outros lugares, não resta nada além de residir nesse desejo e se satisfazer. Anastácia, cidade enganosa, tem um poder, que às vezes se diz maligno e outras vezes benigno: se você trabalha oito horas por dia como minerador de ágatas ônix crisóprasos, a fadiga que dá forma aos seus desejos toma dos desejos a sua forma, e você acha que está se divertindo em Anastácia quando não passa de seu escravo.

Na prática da atividade física com uma forma de acomodação bem-adaptada, o limite do corpo é sistematicamente negligenciado. Dialeticamente, é através dessa agressão que o sujeito se conecta brevemente ao seu próprio corpo (por meio das sensações de dor e cansaço) e mantém o círculo vicioso da reatuação traumática. Não é que nestes casos não se possa gostar e ter prazer durante a atividade física. Na verdade, estes são relatos comuns em quadros de dependência do exercício, na dismorfia muscular e no uso da atividade física como método compensatório nos quadros de bulimia nervosa e anorexia nervosa. Nestes quadros clínicos a atividade física configura-se como mantenedora de um ciclo de perpetuação destes distúrbios, que envolvem uma representação não acurada do corpo (Assunção, Cordas, \& Araújo, 2002; Pope, Phillips, \& Olivardia, 2001).

Uma diferença importante no uso da atividade física como forma de acomodação e de promoção do desenvolvimento é a conexão do sujeito com a realidade concreta de seu corpo. As sensações que emergem do corpo, sejam elas positivas ou negativas, confortáveis ou desconfortáveis, 
todas elas constituem elementos referenciais para o reconhecimento dos limites, das potencialidades, das vulnerabilidades, de sua própria história. Pessoas resilientes confiam nas suas respostas e sensações corporais mesmo não as compreendendo completamente, e estão dispostas a experienciar a si mesmas, mesmo que à primeira vista pareçam vivenciar sensações corporais incongruentes (Levine, \& Frederick, 1999).

O professor de Educação Física pode ser um elemento diferencial entre uma atividade promotora do desenvolvimento da identidade corporal e aquela que acomoda e perpetua o congelamento traumático. Esse profissional deverá compreender que o movimento corporal está envolvido em expressar, muito mais que palavras, aspectos da existência. Nunca um ato é vão, feito ao acaso, ele sempre tem a ver com a história do sujeito e expressa conteúdos conscientes e inconscientes de sua identidade. Essa compreensão não é cognitiva, mas corporal.

Esta nossa forma de abordar o trabalho do professor de Educação Física na escola não ignora as dificuldades com que este profissional se depara em sua rotina de trabaIho, especialmente nas escolas públicas. Devido ao grande volume de trabalho que os profissionais da área assumem, não é raro que esse potencial papel de tutor de resiliência fique esquecido ou em segundo plano. Não obstante, Melillo (2005) afirma que a resiliência pode ser construída mesmo sem utilizar esse conceito explicitamente e que isso ocorre quando os profissionais "(...) se preocupam, mais do que com seu trabalho, com os destinatários” (p.88). Melillo (2005) afirma também que a promoção da resiliência pode ocorrer de forma implícita na escola quando professores constroem com o educando uma relação de amor incondicional, expresso pelo afeto, pelo desenvolvimento da autoestima e pelo estimulo à autonomia e capacidade de solucionar problemas. Cyrulnik, 2005 (p. 68) afirma:

Quando uma criança encontra-se muito próxima de um predador, uma simples mão estendida torna-se um apoio que poderá salvá-la. Mesmo uma conversa anódina constitui um acontecimento que pode modificar o curso de sua existência. É muitas vezes dessa maneira que os professores são eficazes, bem como pela grande quantidade de conhecimentos abstratos que disponibilizam. Eles se tornam tutores de resiliência para uma criança ferida quando criam um acontecimento significativo que assume um valor de referência.

O ponto fundamental para a promoção da resiliência não está no método de ensino utilizado pelo professor, seja este método parcial, global ou misto. Também não é um esporte específico, os conteúdos da Educação Física ou numa determinada atividade o que fará a criança encontrar no professor de Educação Física um tutor de resiliência. Para que a tutoria se efetive, o professor tutor tornará possível à criança: experimentar, descobrir e discernir suas sensações (Levine, \& Kline, 2008); acessar diferentes formas de cuidar de forma sensata, orientada e que esses cuidados produ- zam significados (Cyrulnik, 2005); sentir-se especial (Assis, Avanci, Njaine, \& Pesce, 2008) e compreendida pelo seu ponto de vista (Cyrulnik, 2005). Além disso, o que possibilitará à criança desenvolver e perceber suas habilidades que levam ao processo de resiliência é a postura do professor, aquilo que ele transmite não por palavras, mas pela linguagem corporal, por sua expressão facial e tom de voz ou por sua presença calma (Levine, \& Kline, 2008), por atitudes suas que estabeleçam uma relação de confiança na qual a criança encontre no professor a pessoa que quer ajudá-la e que acredita na sua capacidade de aprender (Melillo, 2005).

Assim, o professor que assume esta postura de professor tutor deve ter desenvolvida sua capacidade de ouvir o outro, de ser tocado por ele sem se desestruturar, de suportar a dor e a angústia de seu aluno. Como afirma Tavares (2003), o professor deve ter uma imagem corporal bem-desenvolvida e já ter lidado com suas perdas, reconhecendo-se como sujeito com potencialidades e limitações. Dessa forma conseguirá oferecer o espaço seguro para o outro identificar-se como sujeito, a partir do ouvir empático; conseguirá compreendê-lo como uma estrutura única, que jamais será inteiramente descrita e explicada, que tem sua fala, suas marcas, sua história singular.

Assim, concluindo nossa argumentação, reconhecemos que o professor de Educação Física tem um grande potencial de se tornar a pessoa que oportuniza um espaço seguro de desenvolvimento da identidade corporal. $O$ exercício físico orientado a este fim pode proporcionar ao indivíduo vivências que sejam promotoras do desenvolvimento da identidade do sujeito, pois é um recurso para a conscientização dos próprios sentimentos, potencialidades e limites do corpo (Rabinor, \& Bilich, 2002). Na prescrição de exercícios, na proposição de jogos e na condução de atividades de lazer, o professor de Educação Física que esteja atento à sua forma de conduzir sua aula poderá tornar-se um tutor de resiliência, criando alicerces para o desenvolvimento do potencial de resiliência de seus alunos que tenham elementos fragmentados na sua identidade corporal (Cyrulnik, 2004; Krueger, 2002). Dessa forma, no contexto de sua competência específica - que é propiciar ao aluno o desenvolvimento motor, melhorar seu condicionamento físico e propiciar-lhe uma ocupação saudável do tempo de lazer, por meio de exercícios orientados, ensino de esportes, proposição de jogos e atividades de lazer -, o professor de Educação Física poderá facilitar o desenvolvimento de uma autoimagem corporal mais positiva.

\section{Referências}

Algoe, S. B., \& Fredrickson, B. L. (2011). Emotional fitness and the movement of affective science: from lab to field. American Psychologist, 66, 35-42.

Assis, S. G., Avanci, J. Q., Njaine, K., \& Pesce, R. P. (2008). Resiliência na adolescência: refletindo com educadores sobre superação de dificuldades. Rio de Janeiro: FIOCRUZ/ENSP/ CLAVES/CNPq. 
Assunção, S. S. M., Cordás, T. A., \& Araújo, L. A. S. B. (2002). Atividade física e transtornos alimentares. Revista de Psiquiatria Clínica, 29, 4-13.

Avalos, L., Tylka,T.L. \& Wood-Barcalow, N. (2005). The Body Appreciation Scale: Development and psychometric evaluation. Body Image, 2, 285-297.

Bentzen, M., Jarlnaes, E., \& Levine, P. (2010) The Body Self in Psychotherapy: A psychomotoric approach to developmental psychology. Em I. Macnaughton (Org.), Body, Breath, \& Consciousness (pp. 51-70). Berkley: North Atlantic Books.

Calvino, I. (1990). As cidades invisíveis. São Paulo: Companhia das letras.

Campbell, A,. \& Hausenblas, H. A. (2009). Effects of Exercise Interventions on Body Image: a meta- analysis. Journal of Health Psychology, 14, 780-793.

Cash, T. (2004). Body Image: past, present, future. Body Image, 1, 1-5.

Cyrulnik, B. (2004) Os Patinhos Feios. São Paulo: Martins Fontes.

Cyrulnik, B. (2005) O Murmúrio dos fantasmas. São Paulo: Martins Fontes.

Cyrulnik, B. (2009) Autobiografia de um espantalho. São Paulo: Martins Fontes.

Doll, B., Dooley, A., \& Turner, A. (2011). The promise and the caution of resilience models for schools. Psychology in the schools, 48, 652-659.

Dolto, F. (2001). A imagem inconsciente do corpo. São Paulo: Perspectiva.

Dyer, J.G., \& McGuinness, T. M. (1996). Resilience: analysis of the concept. Archives of Psychiatric Nursing, 5, 276-282.

Froehlich-Gildhoff, K., \& Roennau-Boese, M. (2012). Prevention of exclusion: the promotion of resilience in early childhood institutions in disadvantaged areas. Journal of Public Health, 20, 131-139.

Grotberg, E. H. (2005). Introdução: novas tendências em resiliência. Em A. Melillo, \& E.N.S Ojeda (Orgs.), Resiliência: descobrindo as próprias fortalezas (pp. 15-22.) Porto Alegre: Artmed.

Guillian, R. (1999). Enhancing the resilience of children and young people in public care by mentoring their talents and interests. Child and Family Social Work,4, 187-196.

Horning, L.E., \& Rouse, K.A. (2002). Resilience in preschoolers and toddlers from low-income families. Early Childhood Education Journal, 29, 155-159.
Iza, D. F. V., \& Mello, M. A. Quietas e caladas: as atividades de movimento com as crianças na Educação Infantil. Educação em revista, 25, 283-302.

Junqueira, M. F. P. S,. \& Deslandes, S. F. (2003). Resiliência e maustratos à criança. Caderno de Saúde Pública, 19, 227-235.

Krueger, D.W. (2002) Integrating Body Self and Psychological Self: creating a new history in psychoanalysis and psychotherapy. Nova lorque: Brunner-Routledge.

Krueger, D.W. (2002a). Developmental and Psychodynamic Perspectives on Body-Image Change. Em T. Cash, \& T. Pruzinsky. (Orgs.), Body Image: Handbook of Theory, Research, and Clinical Practice (pp. 255-271). Nova lorque: The Guilford Press.

Krueger, D.W. (2001). Body Self: Development, Psychopathologies and Psychoanalytic Significance. Psychoanalitic Study of Child, 56, 238-262.

Levine, P., \& Frederick, A. (1999). O Despertar do Tigre. São Paulo: Summus.

Levine, P., \& Kline, M. (2007). Trauma through a child's eyes: awakening the ordinary miracle of healing. Berkley: North Atlantic Books.

Melillo, A. (2005). Resiliência e Educação. Em A. Melillo, \& E.N.S Ojeda (Orgs.), Resiliência: descobrindo as próprias fortalezas (pp. 87-101) Porto Alegre: Artmed.

Melillo, A., Estamatti, M., \& Cuestas, A. (2005). Alguns fundamentos psicológicos do conceito de resiliência. Em A. Melillo, \& E.N.S Ojeda (Orgs.), Resiliência: descobrindo as próprias fortalezas (pp. 59-72). Porto Alegre: Artmed.

Melillo, A., \& Ojeda, E.N.S. (2005). Resiliência: descobrindo as próprias fortalezas. Porto Alegre: Artmed.

Morgan, P. (2010). 'Get Up. Stand Up.' Riding to resilience on a surfboard. Child and Family Social Work, 15, 56-65.

Rabinor, J. R., \& Bilich, M. A. (2002). Experimental Approaches to Changing Body Image. Em T. Cash, \& T. Pruzinsky (Orgs.), Body Image: Handbook of Theory, Research, and Clinical Practice (pp. 469-477). Nova lorque: The Guilford Press.

Pope, H. G., Phillips, K. A., \& Olivardia, R. (2000). The Adonis Complex. Nova lorque: The Free Press.

Schilder, P. (1980). A Imagem do Corpo: as energias construtivas da Psiquê. São Paulo: Martins Fontes.

Shontz, F. C. (1969). Perceptual and Cognitive Aspects of Body Experience. Londres: Academic press. 
Smolak, L. (2011). Body Image development in childhood. Em T. Cash, \& L. Smolak (Orgs), Body Image: a handbook of science, practice and prevention (pp. 67-75). Nova lorque: The Guilford Press.
Tavares, M. C. G. C. F. (2003). Imagem corporal: conceito e desenvolvimento. Bareuri: Manole.

Recebido em: 25/06/2013

1a Reformulação em: 17/12/2013

$2^{\text {a }}$ Reformulação em: 27/02/2014

Aprovado em: 04/04/2014

\section{Sobre as autoras}

Angela Nogueira Neves (angelanneves@yahoo.com.br)

Doutora em Educação Física - Escola de Educação Física do Exército, Rio de Janeiro.

Karina Mayumi Hirata (karinamahi@hotmail.com)

Licenciada em Educação Física - Universidade Estadual de Campinas

Maria da Consolação Gomes Cunha Fernandes Tavares (mcons@fef.unicamp.br)

Professora Titular - Universidade Estadual de Campinas

Pesquisa realizada sem financiamento 